\title{
Positive Regulation of Pulmonary Antioxidant Enzyme Gene Expression by Prenatal Thyrotropin Releasing Hormone Plus Dexamethasone Treatment in Premature Rats Exposed to Hyperoxia
}

\author{
YOUWEI CHEN, ILENE R.S. SOSENKO, AND LEE FRANK \\ Pulmonary Research Center, Departments of Pediatrics and Medicine, University of Miami School of \\ Medicine, Miami, Florida 33101
}

\begin{abstract}
Prenatal administration of thyrotropin releasing hormone
(TRH) plus dexamethasone (DEX) to pregnant rats produces significantly depressed fetal lung antioxidant enzyme (AOE) activities and AOE mRNA levels in late gestation. Because of this negative regulation of $\mathrm{AOE}$ gene expression in the late fetal lung, we hypothesized that hormonally pretreated prematurely delivered rats might demonstrate inferior tolerance to prolonged hyperoxia. Litters of prenatal TRH+DEX-treated and shamtreated prematurely delivered rat pups (gestational d 21 of 22) were randomized to either $>95 \% \mathrm{O}_{2}$ or room air for up to $14 \mathrm{~d}$. The right lungs of 2- and 7-d exposure pups were assayed for AOE activities; the left lungs of the same pups were used to quantitate the concentrations of AOE mRNA by solution hybridization. The prenatal TRH+DEX-treated pups were able to induce adaptive lung $\mathrm{AOE}$ mRNA and activity responses to hyperoxia by $2 \mathrm{~d}$ of exposure; and by $7 \mathrm{~d}$ in $\mathrm{O}_{2}$ they showed greater increases in AOE mRNA concentrations and AOE activities in response to hyperoxic challenge compared with the sham-treated controls. Lung lipid surfactant measurements after hyperoxia were not affected by prenatal TRH+DEX treatment. In addition, TRH+DEX-pretreated premature rats did not show the hypothesized increased susceptibility to $\mathrm{O}_{2}$-induced lung damage and lethality, but, in fact, had slightly improved hyper-
\end{abstract}

oxic survival (d 3-7 of $\mathrm{O}_{2}$ exposure) compared with shamtreated controls. Exposure to hyperoxia significantly reduced serum triiodothyronine and thyroxine levels in the sham-control pups. These findings suggest that although TRH+DEXpretreated premature rats have decreased lung AOE gene expression at the time of preterm delivery, subsequent hyperoxic exposure is able to convert AOE gene expression to positive regulation which results in more rapid and greater increases in protective AOE activity levels. This regulation is likely mediated differently for the individual AOE. (Pediatr Res 37: 611-616, 1995)

$\quad$ Abbreviations
TRH, thyrotropin releasing hormone
DEX, dexamethasone
AOE, antioxidant enzyme
CuZnSOD, copper-zinc superoxide dismutase
MnSOD, manganese superoxide dismutase
CAT, catalase
GP, glutathione peroxidase
DSPC, disaturated phosphatidylcholine
$\mathbf{T}_{\mathbf{3}}$, triiodothyronine
$\mathbf{T}_{\mathbf{4}}$, thyroxine

Prenatal hormonal therapy with maternal administration of a combination of TRH and glucocorticoids is now being extensively tested clinically in threatened premature deliveries to try to rapidly stimulate lung maturation and reduce the incidence and severity of respiratory distress syndrome in premature

Received May 20, 1994; accepted December 1, 1994.

Correspondence and reprints: Youwei Chen, M.D., Pulmonary Research (R-120), University of Miami School of Medicine, P.O. Box 016960, Miami, FL 33101.

Supported by the University of Miami School of Medicine, Pulmonary Research Center, Departments of Pediatrics and Medicine, and by American Lung Association of Florida Career Investigator Award (L.F.).

Presented in part at the 1994 annual meeting of the Society for Pediatric Research, Seattle, WA. infants (1-3). It has been previously demonstrated by our laboratories that although prenatal administration of TRH+DEX to pregnant rats accelerates surfactant system development in the late fetal lung, this same hormonal treatment significantly decreases the normal fetal lung AOE (SOD, CAT, and GP) activity elevations in late gestation (4). This hormonal effect appears to depend on a pretranslational/ transcriptional mechanism involving decreased AOE mRNA levels (5). When full-term newborn rats prenatally treated with TRH+DEX were exposed to prolonged hyperoxia, results showed that although these newborns manifested lower baseline AOE activities at birth than control term newborns, the 
hormone-treated pups were still able to induce an adaptive lung AOE response to hyperoxic exposure of equal or even greater magnitude compared with $\mathrm{O}_{2}$-exposed control offspring (4). Moreover, what was most interesting and still unexplained in this previous study was the consistent finding that, despite their greater pulmonary $\mathrm{AOE}$ response to hyperoxic challenge, the prenatal TRH+DEX-treated full-term newborn rats showed evidence of decreased hyperoxic survival and $\mathrm{O}_{2}$ tolerance compared with $\mathrm{O}_{2}$ control pups (6).

Based on these previous findings, we hypothesized that prematurely delivered rat pups prenatally treated with TRH+DEX might likewise demonstrate inferior tolerance to prolonged hyperoxia just as full-term TRH + DEX rat pups did. To test this hypothesis, we used a prematurely delivered rat model (7) which we felt was more reflective of the clinical use of this combined hormonal treatment. We performed studies in which prenatal TRH+DEX-treated and sham-treated control premature rat pups were simultaneously exposed to prolonged hyperoxic exposure and various parameters of relative $\mathrm{O}_{2}$ tolerance/susceptibility were compared between the two groups.

\section{METHODS}

Animals and treatment. Adult breeder Sprague-Dawley albino rats were obtained from Charles River Laboratories (Wellington, MA). Breeding was accomplished by placing two female rats in the same cage with one male overnight. Probable pregnancy was determined by a positive vaginal sperm smear the next morning, and the onset of gestation was considered to be the midpoint of the cohabitation period. The timedpregnancy rats were maintained on standard laboratory food and water ad libitum and were kept on a 12-h light/dark cycle in the accredited University of Miami Animal Care Facilities. All portions of the experimental protocol were preapproved by the University of Miami Animal Research Welfare Committee.

At $48 \mathrm{~h}$ before premature delivery at gestational d 21 , timed-pregnancy rats were divided at random into hormonal treatment or sham-control groups. For the group receiving prenatal TRH+DEX combination therapy, prenatal TRH (Bachem Inc., Torrance, CA) was administered as a loading dose of TRH $(25 \mu \mathrm{g} / \mathrm{kg}$, s.c. $)$ at $48 \mathrm{~h}$ before premature delivery, immediately after the s.c. implantation of an Alzet osmotic minipump (Alza Corp., Palo Alto, CA) through which continuous TRH was administered $(100 \mu \mathrm{g} / \mathrm{kg} / \mathrm{d})$. In addition, these same dams received prenatal DEX (Steris Laboratories, Inc., Phoenix, AZ) at a dose of $0.4 \mathrm{mg} / \mathrm{kg}$ intraperitoneally at 48 and $24 \mathrm{~h}$ before premature delivery. The control pregnant rat group received an equivolume s.c. injection of saline instead of TRH, and a "sham" operation using the same ketamine/xylazine anesthesia (ketamine:xylazine, $45 \mathrm{mg} / \mathrm{kg}: 5 \mathrm{mg} / \mathrm{kg}$, intraperitoneal injection), as well as an equivolume $(0.5 \mathrm{~mL} / 100 \mathrm{~g})$ of intraperitoneal saline instead of DEX. All of the above hormonal treatment procedures and dosages of TRH and DEX were identical to those used in previously reported studies from our laboratories (4-6).

At $21 \mathrm{~d}$ of gestation (term $=22 \mathrm{~d}$ ), pregnant rats were anesthetized by intraperitoneal injection of ketamine/xylazine (dose as above) and hysterotomy was performed. The newly delivered pups were rapidly resuscitated by removing the surrounding membranes, drying them vigorously, warming them on heating pads, and applying low flow $\mathrm{O}_{2}(\sim 30 \%)$ for $\sim 30 \mathrm{~min}$.

Hyperoxic exposure. Shortly after delivery and stabilization, all the surviving 21-d premature pups of three to five equivalently treated litters were first pooled together and then randomly redistributed to surrogate rat dams that had recently delivered at term. For each group (TRH+DEX or sham-treated control), one half of the reconstituted litters were placed in $>95 \% \mathrm{O}_{2}$ exposure chambers and one half remained in room air. Some nonexperimental full-term newborn rat pups (marked by tail snip) were added at $24 \mathrm{~h}$ and/or $48 \mathrm{~h}$ of exposure when necessary to readjust the litter sizes to $10-12$ pups per dam to ensure equal litter sizes for equivalent nutrition. The details of the procedures and conditions of hyperoxic exposures have been previously described (7). Survival was noted daily during the 14-d exposure period.

Biochemical analyses. Randomly selected $\mathrm{O}_{2}$-exposed and air-exposed pups from each group were killed by an intraperitoneal overdose of pentobarbital after either 2 or $7 \mathrm{~d}$ of exposure. The procedures of lung perfusion have been previously described (7). The left lungs of two pups were pooled for measuring AOE mRNA concentrations; the right lungs of the same pups were pooled for assaying AOE activities.

AOE mRNA quantitation. The rat complementary RNA for CuZnSOD, MnSOD, CAT, and GP were prepared as previously described $(5,8,9)$. Total nucleic acids were extracted by phenol-chloroform extraction of the left lung tissue homogenate (9). Quantitation of each AOE mRNA was achieved using the solution hybridization assay of Durnam and Palmiter (10). Results of the AOE mRNA concentrations were expressed as the specific AOE mRNA molecules per mg DNA.

AOE activity assays. The right lung tissues were homogenized in cold $2.5 \mathrm{mM}$ potassium phosphate buffer ( $\mathrm{pH} 7.8$ ) in an Omni homogenizer (Omni International Inc., Waterbury, CT). The homogenates were centrifuged at $27000 \times g$ for 45 $\min$ at $4^{\circ} \mathrm{C}$. The supernatant fractions were then dialyzed overnight against three changes of 50 volumes of $2.5 \mathrm{mM}$ potassium phosphate buffer ( $\mathrm{pH} 7.8$ ) with $0.1 \mathrm{mM}$ EDTA and were subsequently used for analyses of $\mathrm{AOE}$ activities using standard spectrophotometric assays for SOD (cytochrome $c$ reduction rate by xanthine-xanthine oxidase) (11), CAT $\left(\mathrm{H}_{2} \mathrm{O}_{2}\right.$ consumption rate) (12), and GP (NADPH oxidation rate with cumene hydroperoxide substrate) (13). The method of differential cyanide inhibition was used to quantitate cytosolic CuZnSOD and mitochondrial MnSOD activities (14). All enzyme activities were expressed as activity units per mg DNA. DNA in aliquots of the lung homogenates used for AOE mRNA or for $\mathrm{AOE}$ activity was extracted and measured using purified calf thymus DNA (Sigma Chemical Co., St. Louis, MO) as a standard (15).

Surfactant phospholipids and DSPC. The lipids were extracted from lung homogenates using the method of Bligh and Dyer (16). A portion of the lipid extracts was used to isolate DSPC according to Mason et al. (17). The total phospholipids and DSPC content were measured by phosphorus determina- 
tions in these fraction (18). A known quantity of ${ }^{14} \mathrm{C}$ dipalmitoyl-phosphatidylcholine (DuPont NEN, Boston, MA) was added before lipid extraction to estimate and correct for sequential losses. Lipids were expressed as $\mathrm{mg} / \mathrm{mg}$ protein. Protein was measured by the Folin phenol reagent method (19).

Lung pathologic analyses. Randomly selected animals from each group at 7 and $14 \mathrm{~d}$ of exposure were killed as above. Unperfused, uninflated left lung lobes were tied off and removed for assessing lung wet weight/dry weight ratios $\left[80^{\circ} \mathrm{C}\right.$ oven; lungs dried until constant weight found $(72 \mathrm{~h})]$. For microscopic studies, the right lungs of randomly selected animals at $7 \mathrm{~d}$ of exposure were fixed in situ via a tracheal cannula at a constant inflation pressure of $20 \mathrm{~cm} \mathrm{H}_{2} \mathrm{O}$ (fixative, $10 \%$ buffered formalin). The coded hematoxylin and eosinstained lung sections (right upper, middle, and lower lobes) were examined for pathologic changes by two investigators who were looking for evidence of interstitial, perivascular/ peribronchiolar, and intraalveolar edema, and lung hemorrhage.

Serum hormone assay. Hormone assays for serum $\mathrm{T}_{3}$ and $\mathrm{T}_{4}$ were done using specific RIA kits (Incstar Corporation, Stillwater, MN) in TRH+DEX-treated and sham-treated control pups after $14 \mathrm{~d}$ of exposure.

Statistical analyses. Comparative survival data and incidence of intraalveolar edema were compared by $\chi^{2}$ testing. Four group comparisons (TRH $+\mathrm{DEX}$ air, TRH+DEX $\mathrm{O}_{2}$, sham-treated control air, and sham-treated control $\mathrm{O}_{2}$ ) were made by analysis of variance and Duncan's multiple range test. Kramer's extension of Duncan's test was used in cases of unequal number of replications (20). For all statistical tests, a $p<0.05$ value was considered a significant difference between the compared values.

\section{RESULTS}

Survival in hyperoxia. Initial survival at $\sim 30 \mathrm{~min}$ after premature delivery averaged $77 \%$ (330/431, number alive/total number delivered) for sham-treated control rat pups and $78 \%$ (272/349) for TRH+DEX-treated rat pups. The composite survival rates of TRH+DEX-treated and sham-treated control premature rat pups during $14 \mathrm{~d}$ of hyperoxia are illustrated in Figure 1. Premature rats pretreated with TRH+DEX did not demonstrate the hypothesized inferior tolerance to hyperoxic challenge but actually had slightly improved $\mathrm{O}_{2}$ survival versus sham-treated control rats between exposure $\mathrm{d} 3$ and 7 .

Lung biochemical responses to hyperoxia. The comparative responses of the pulmonary $\mathrm{AOE}$ to hyperoxic challenge in the TRH+DEX-treated and sham-treated control premature rat pups are shown in Tables 1 and 2 (at $2 \mathrm{~d}$ exposure) and Figures 2 and 3 (at $7 \mathrm{~d}$ exposure). By $2 \mathrm{~d}$ in hyperoxia, the prenatal TRH+DEX pups were able to elevate adaptive lung AOE mRNA levels (Table 1) and increase their CAT and GP activity response to hyperoxic exposure compared with no significant changes in CAT activity and slightly decreased GP activity in the sham-treated control- $\mathrm{O}_{2}$ pups (Table 2). After $7 \mathrm{~d}$ in hyperoxia, the four AOE mRNA levels (Fig. 2) significantly increased in the TRH+DEX group compared with its respective air group and even greater increases in AOE mRNA levels were present in the TRH + DEX $\mathrm{O}_{2}$ group when compared with the sham-treated control- $\mathrm{O}_{2}$ group (with the single exception of MnSOD mRNA). The four AOE activities were also consistently greater in the TRH+DEX group than the sham-treated control $\mathrm{O}_{2}$ pups (Fig. 3).

In contrast to the lung $\mathrm{AOE}$ data, no significant differences in response to $7 \mathrm{~d}$ of hyperoxia were found in lung DSPC content between the TRH+DEX $(0.062 \pm 0.007)$ and sham-

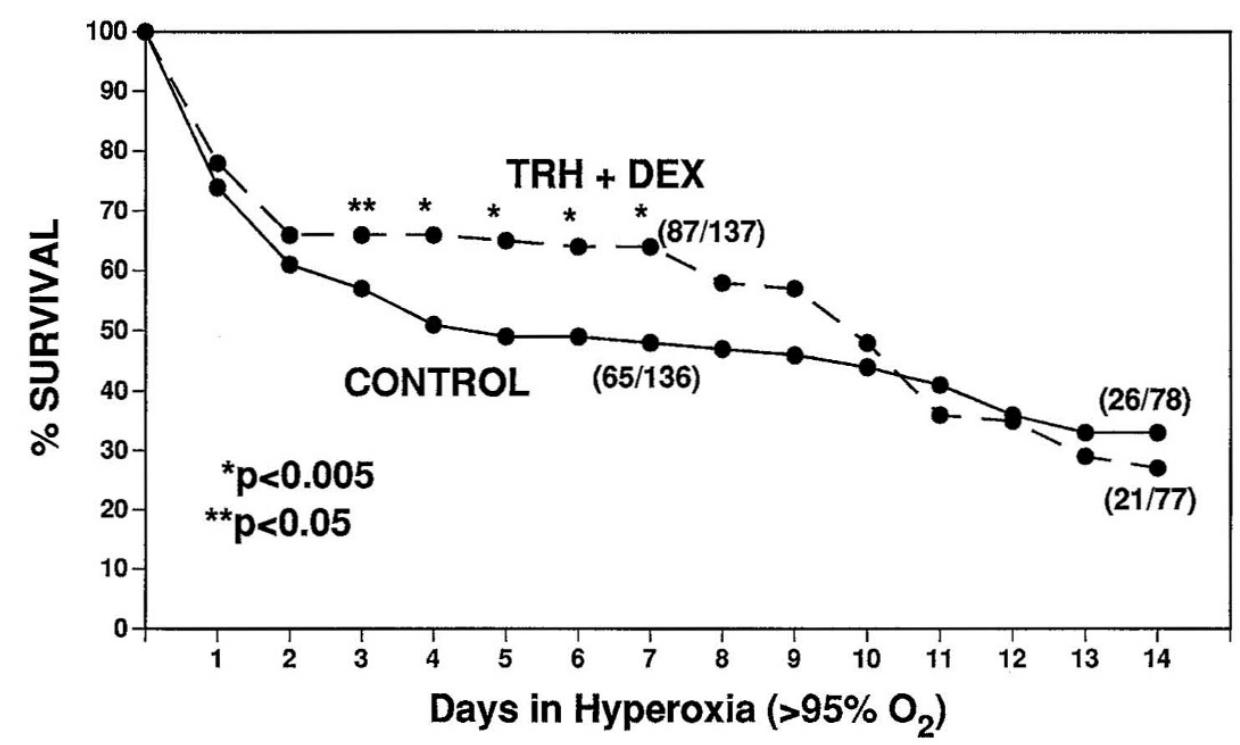

Figure 1. Survival of TRH+DEX-pretreated and control premature rat pups in $>95 \% \mathrm{O}_{2}$ for $14 \mathrm{~d}\left(n / n\right.$, number alive/number put in $\left.\mathrm{O}_{2}\right) .{ }^{*}, p<0.005$ and $* *$, $p<0.05$ for the two $\mathrm{O}_{2}$-exposed group survival rate comparisons. For the premature rat pups maintained in air, the subsequent survival rates for the TRH+DEX-treated group were $83 \%$ (at $24 \mathrm{~h}$ ), $75 \%$ (at $48 \mathrm{~h}$ ), and $75 \%$ (2-14 d of exposure). [ $p<0.001$ compared with survival rates of $57 \%$ (at $24 \mathrm{~h}$ ), $52 \%$ (at $48 \mathrm{~h}$ ), and $52 \%$ ( 2 to $14 \mathrm{~d}$ of exposure), respectively, for the control pups.] Note: The initial drop in survival during the first $48 \mathrm{~h}$-comparable for both groups-is likely not due to pulmonary $\mathrm{O}_{2}$ toxicity. 
Table 1. Comparative lung AOE mRNA concentrations at $2 d$ of hyperoxic exposure

\begin{tabular}{|c|c|c|c|c|}
\hline \multirow[b]{2}{*}{ Group } & \multicolumn{4}{|c|}{ AOE mRNA (molecules/mg DNA $\times 10^{-12}$ ) } \\
\hline & CuZnSOD & MnSOD & CAT & GP \\
\hline Control-air & $28.4 \pm 1.2$ & $3.57 \pm 0.29$ & $15.1 \pm 0.9$ & $16.1 \pm 2.0$ \\
\hline Control- $\mathrm{O}_{2}$ & $\begin{array}{c}38.3 \pm 3.5^{*} \\
(\uparrow 35 \%)\end{array}$ & $\begin{array}{c}3.51 \pm 0.31 \\
(\downarrow 2 \%)\end{array}$ & $\begin{array}{c}13.1 \pm 0.8 \\
(\downarrow 14 \%)\end{array}$ & $\begin{array}{l}9.9 \pm 1.2 * \\
(\downarrow 38 \%)\end{array}$ \\
\hline TRH+DEX-air & $20.9 \pm 2.7$ & $3.11 \pm 0.21$ & $9.8 \pm 0.7$ & $11.0 \pm 2.0$ \\
\hline $\mathrm{TRH}+\mathrm{DEX}-\mathrm{O}_{2}$ & $\begin{array}{c}42.2 \pm 5.8^{*} \\
(\uparrow 102 \%) \\
\end{array}$ & $\begin{array}{c}4.13 \pm 0.30 \\
(\uparrow 32 \%) \\
\end{array}$ & $\begin{array}{c}14.0 \pm 1.5^{*} \\
(\uparrow 42 \%) \\
\end{array}$ & $\begin{array}{c}13.6 \pm 2.0 \\
(\uparrow 23 \%) \\
\end{array}$ \\
\hline
\end{tabular}

Values are mean \pm SEM for four to six samples/group using rat left lungs. ${ }^{*} p<0.05 v s$ respective air group.

Table 2. Comparative pulmonary AOE activities at $2 d$ of hyperoxic exposure

\begin{tabular}{lcccc}
\hline & \multicolumn{4}{c}{ AOE activity (unit/mg DNA) } \\
\cline { 2 - 5 } \multicolumn{1}{c}{ Group } & CuZnSOD & MnSOD & CAT & GP \\
\hline Control-air & $19.3 \pm 0.4$ & $3.25 \pm 0.20$ & $63.7 \pm 4.7$ & $0.22 \pm 0.01$ \\
Control-O & $20.7 \pm 0.7$ & $3.27 \pm 0.19$ & $71.3 \pm 3.7$ & $0.18 \pm 0.01$ \\
& $(\uparrow 9 \%)$ & $(\uparrow 1 \%)$ & $(\uparrow 12 \%)$ & $(\downarrow 15 \%)$ \\
TRH+DEX-air & $19.4 \pm 0.4$ & $2.91 \pm 0.25$ & $61.9 \pm 2.9$ & $0.20 \pm 0.01$ \\
TRH+DEX-O & $20.9 \pm 0.7$ & $3.36 \pm 0.24$ & $82.2 \pm 1.9 *$ & $0.23 \pm 0.01 \uparrow$ \\
& $(\uparrow 8 \%)$ & $(\uparrow 15 \%)$ & $(\uparrow 33 \%)$ & $(\uparrow 17 \%)$ \\
\hline
\end{tabular}

Values are mean \pm SEM for four to six samples/group using rat right lungs from same samples as Table 1.

${ }^{*} p<0.01 v s \mathrm{TRH}+\mathrm{DEX}$-air group.

$\dagger p<0.05 v s$ control- $\mathrm{O}_{2}$ group.

treated control pups $(0.058 \pm 0.005)$. (Average air DSPC value $=0.051 \pm 0.003 \mathrm{mg} / \mathrm{mg}$ protein; mean $\pm \mathrm{SEM}, n=8$ samples/group, $p>0.05$.) There were also no differences with $7 \mathrm{~d}$ of hyperoxia in lung total phospholipid content between the TRH+DEX $(0.284 \pm 0.019)$ and sham-treated control pups $(0.263 \pm 0.013)$. (Average air control total phospholipid value $=0.274 \pm 0.008 \mathrm{mg} / \mathrm{mg}$ protein; $p>0.05$.)

Lung pathologic analyses. The comparative lung wet weight/dry weight ratios (a reflection of pulmonary edema) after 7 and $14 \mathrm{~d}$ of hyperoxia for the TRH+DEX and shamtreated control groups are summarized in Table 3. Whereas no differences were present between groups after $7 \mathrm{~d}$ hyperoxic exposure, after $14 \mathrm{~d}$ of hyperoxia, TRH+DEX-treated preterm pups demonstrated a significantly smaller increase in lung wet/dry weight ratio compared with sham-treated control preterm pups, suggesting less pulmonary edema. As more definitive evidence of advanced $\mathrm{O}_{2}$ toxicity, light microscopic examination showed a similar incidence of intraalveolar edema in the two $\mathrm{O}_{2}$ groups after $7 \mathrm{~d}$ of exposure. The number with intraalveolar edema fluid per total number of coded lung sections examined was $3 / 30(10 \%)$ for the TRH+DEX-treated $\mathrm{O}_{2}$ group, and 2/15 (13\%) for the sham-treated control $\mathrm{O}_{2}$ group $(p>0.05)$. The TRH + DEX-treated premature pups did not show the hypothesized increase in susceptibility to $\mathrm{O}_{2}$ induced lung damage.

Hormone assays. The $\mathrm{T}_{3}$ and $\mathrm{T}_{4}$ serum levels in TRH+DEX-treated and sham-treated control offspring after 14 $\mathrm{d}$ in $>95 \% \mathrm{O}_{2}$ or room air exposure are shown in Table 4. Prenatal TRH+DEX treatment resulted in consistently increased $\mathrm{T}_{3}$ and $\mathrm{T}_{4}$ serum levels. Exposure to $14 \mathrm{~d}$ of high $\mathrm{O}_{2}$ significantly reduced serum $\mathrm{T}_{3}$ and $\mathrm{T}_{4}$ levels in sham-treated control pups and reduced the serum $\mathrm{T}_{4}$ level in the prenatal TRH+DEX-treated group.

\section{DISCUSSION}

The effects of prenatal hormonal treatment with the combination of TRH plus glucocorticoids on the maturation of the fetal lung and the surfactant system have been tested in both extensive animal studies and recent clinical studies. The clinical trials with combined TRH and glucocorticoid treatment have shown a decreased incidence of chronic lung disease (bronchopulmonary dysplasia) in very-low-birth weight infants, but surprisingly no significant decrease in the incidence or severity of respiratory distress syndrome $(2,3)$.

\begin{tabular}{ll}
$\square$ Control-Air & $\square$ Control-O \\
TRH+DEX-Air & TRH+DEX-O \\
\hline
\end{tabular}
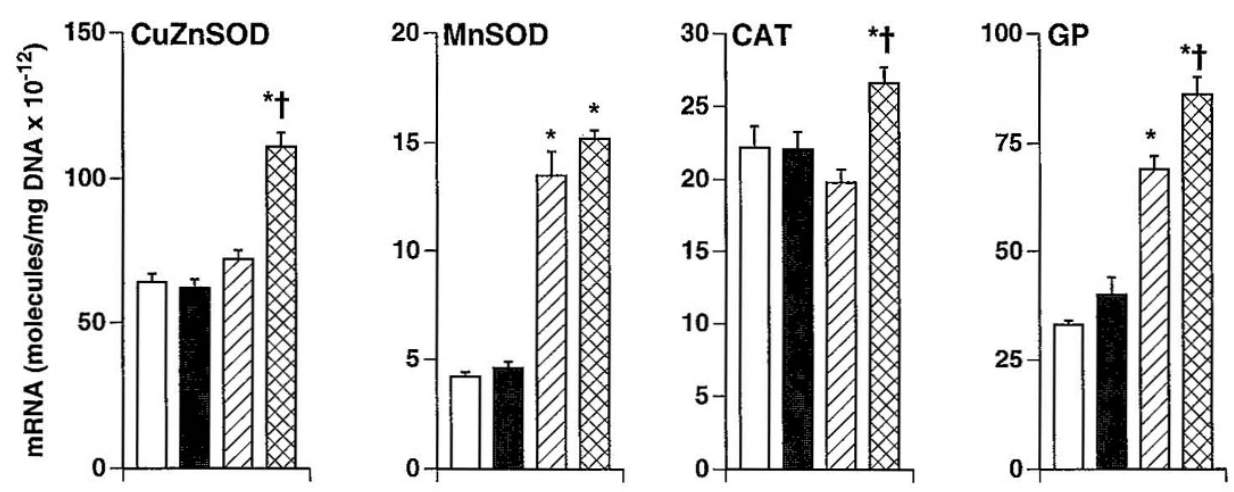

Figure 2. Comparative lung AOE mRNA concentrations of TRH+DEX-pretreated and control premature rat pups at $7 \mathrm{~d}$ of hyperoxic $\left(>95 \% \mathrm{O}_{2}\right)$ exposure. Rat left lungs were assayed for CuZnSOD mRNA, MnSOD mRNA, CAT mRNA, and GP mRNA by solution hybridization using respective ${ }^{35} \mathrm{~S}-1$ labeled complementary RNA probes. Values are based on six lung samples/group; bars indicate mean \pm SEM. ${ }^{*}, p<0.05$ for $\mathrm{O}_{2}$ group $v s$ respective air group. $\dagger, p$ $<0.01$ for TRH+DEX $\mathrm{O}_{2}$ group vs control- $\mathrm{O}_{2}$ group values. 


$\begin{array}{ll}\square \text { Control-Air } & \square \text { Control- } \mathrm{O}_{2} \\ \text { TRH+DEX-Air } & \text { TRH+DEX-O }\end{array}$
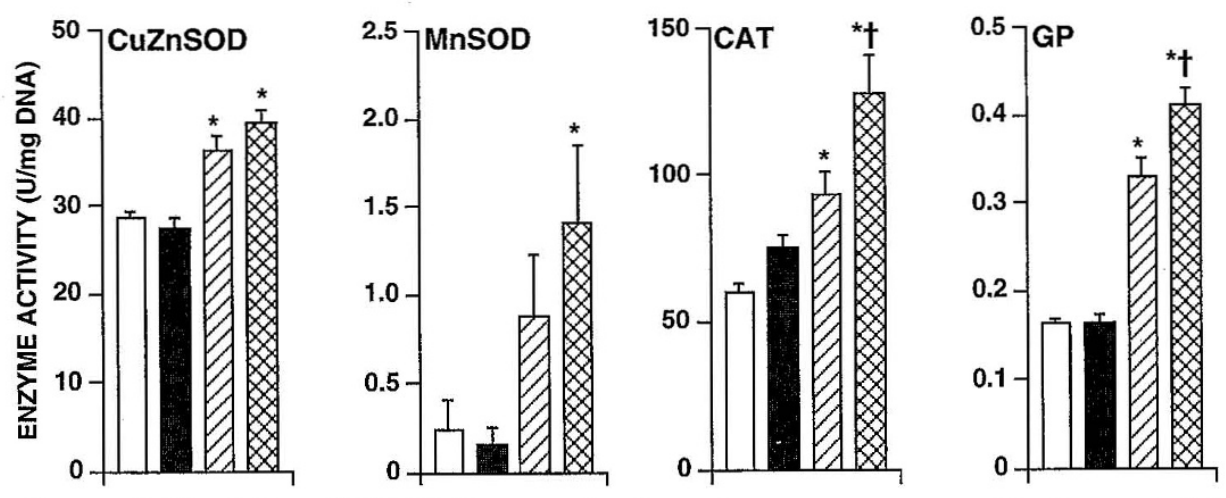

Figure 3. Comparative pulmonary $\mathrm{AOE}$ activities of TRH+DEX-pretreated and control premature rat pups at $7 \mathrm{~d}$ of hyperoxic $\left(>95 \% \mathrm{O}_{2}\right)$ exposure $v s$ room air AOE activity levels. Rat right lungs from the same samples as Figure 2 were assayed for CuZnSOD, MnSOD, CAT, and GP activities. Values are based on six lung samples/group; bars indicate mean \pm SEM. ${ }^{*}, p<0.01$ for $\mathrm{O}_{2}$ group $v s$ respective air group. $\dagger, p<0.01$ for TRH $+\mathrm{DEX} \mathrm{O}_{2}$ group $v s$ control- $\mathrm{O}_{2}$ group values.

Table 3. Comparative lung wet/dry weight ratio after hyperoxic exposure

\begin{tabular}{ccc}
\hline \multicolumn{1}{c}{ Exposure } & $7 \mathrm{~d}$ & $14 \mathrm{~d}$ \\
\hline Control-air & $5.17 \pm 0.07$ & $4.92 \pm 0.03$ \\
Control-O $_{2}$ & $5.24 \pm 0.14$ & $6.76 \pm 0.26^{*}$ \\
& $(\uparrow 1 \%)$ & $(\uparrow 37 \%)$ \\
TRH+DEX-air & $5.29 \pm 0.09$ & $5.03 \pm 0.03$ \\
TRH + DEX-O & $5.47 \pm 0.12$ & $6.10 \pm 0.10^{*} \dagger$ \\
& $(\uparrow 3 \%)$ & $(\uparrow 21 \%)$ \\
\hline
\end{tabular}

Values are mean \pm SEM for five to 11 samples/group for $7 \mathrm{~d}$ of exposure and 12 to 15 samples/group for $14 \mathrm{~d}$ of exposure.

${ }^{*} p<0.01 v s$ respective air group.

$\dagger p<0.01$ vs control- $\mathrm{O}_{2}$ group.

Table 4. Serum $T_{3}$ and $T_{4}$ levels in TRH+DEX-treated and control offspring after $14 \mathrm{~d}$ in $>95 \% \mathrm{O}_{2}$ or room air

\begin{tabular}{lll}
\hline & $\mathrm{T}_{3}(\mathrm{nmol} / \mathrm{L})$ & $\mathrm{T}_{4}(\mathrm{nmol} / \mathrm{L})$ \\
\hline Control-air & $0.66 \pm 0.09$ & $48.4 \pm 2.3$ \\
Control-O & $0.32 \pm 0.10^{*}$ & $29.7 \pm 4.0^{*}$ \\
TRH+DEX-air & $1.16 \pm 0.11 \dagger$ & $60.0 \pm 3.7 \dagger$ \\
TRH+DEX-O & $1.24 \pm 0.17 \dagger$ & $42.6 \pm 4.7^{*} \dagger$ \\
\hline
\end{tabular}

Values are mean \pm SEM for seven to 13 samples/group.

${ }^{*} p<0.05$ vs respective air group.

$\dagger p<0.05$ for TRH+DEX group $v s$ respective control-air or control- $\mathrm{O}_{2}$.

The premature rat model using 21-d gestation rat pups (7) in the present study provides an appropriate model for investigating prenatal TRH and glucocorticoid treatment (relevant to the human clinical prenatal use), especially because the previously reported full-term animal data (6) strongly imply negative effects on hyperoxic tolerance associated with prenatal TRH+DEX treatment. Our original hypothesis in the present study was that premature rat pups prenatally treated with TRH+DEX would demonstrate inferior tolerance to prolonged hyperoxia, similar to what had been found for full-term TRH+DEX-treated rat pups. Unexpectedly, we found that TRH+DEX-pretreated prematurely delivered pups (unlike hormonally treated term newborns) had transiently improved hyperoxic survival and no greater sensitivity to pulmonary $\mathrm{O}_{2}$ toxicity than the sham-treated control pups. These discordant results suggest different effects of prenatal hormonal treatment on preterm versus full-term rat pups, because all hormonal treatment procedures and dosages of TRH and DEX were identical for both studies except for the 24-h difference in the timing of the gestational administration of prenatal $\mathrm{TRH}+\mathrm{DEX}$.

The molecular biology studies described herein were undertaken to provide insight into the regulatory mechanism by which hormonal intervention (TRH+DEX) might be controlling the normal gene expression of the protective AOE system under subsequent hyperoxic conditions. Our findings suggest that the regulation of lung AOE gene expression is complex under hyperoxic conditions. The prematurely delivered rats pretreated with $\mathrm{TRH}+\mathrm{DEX}$ were previously found to have lowered lung AOE gene expression (depressed AOE activities and $\mathrm{AOE}$ mRNA levels) at preterm delivery at $\mathrm{d} 21(4,5)$. Similarly, when examined at $2 \mathrm{~d}$ postnatal age after room air exposure, their pulmonary AOE mRNA levels remained lower in the premature TRH+DEX group compared with the shamtreated group. However, hyperoxic exposure of premature TRH+DEX-treated pups was able to switch AOE gene expression from negative regulation to positive regulation and result in more rapid and even greater increases in protective AOE activity levels than in sham-treated control premature pups exposed to high $\mathrm{O}_{2}$.

Previous studies from our own laboratories have demonstrated that normal perinatal gene expression of the four $\mathrm{AOE}$ is not coordinately regulated (8). Other studies suggest this is true also under hyperoxic conditions. For example, differential regulation of specific AOE in response to oxidants (21) or to hyperoxia (22) in vitro was reported recently in cultured human cells and in hamster tracheal epithelial cells. A recent detailed study by Clerch and Massaro (23) of neonatal rats exposed to hyperoxia has also suggested that lung AOE gene expression is 
differentially regulated in high $\mathrm{O}_{2}$. Our data suggest that AOE gene expression does not appear to be coordinately regulated in the premature rat lung under hyperoxic conditions and/or plus hormonal intervention. For example, in the sham-treated premature rat, lung CAT mRNA concentration decreased $11 \%$ with hyperoxic exposure for $7 \mathrm{~d}$, whereas CAT activity increased $56 \%$, suggesting a translational/posttranslational mechanism of CAT gene expression in the premature rat lung exposed to hyperoxia. The very similar GP activity (102\%) and mRNA $(108 \%)$ responses to hyperoxia $(7 \mathrm{~d})$, however, point to regulation of GP in hyperoxia at a pretranslational level. The effects of prenatal TRH+DEX administration on the premature lung AOE responses to hyperoxia seem to indicate activation of other means of regulation. For example, for the TRH+DEX group, we found that the CAT response to hyperoxia consists of an mRNA increase of $20 \%$ and activity increase of $72 \%$, which may represent a combined pretranslational and a translational/ posttranslational mechanism of gene expression in this group's response to hyperoxia. This appears to be the case for GP as well in the TRH+DEX group exposed to hyperoxia (i.e., more complex AOE gene expression responses than in the sham control group). However, more definitive conclusions about the mechanism(s) of AOE gene expression still depend on further studies to determine whether or not comparative AOE mRNA stabilities (half-lives) are also altered under hyperoxic conditions in either or both the sham control and TRH+DEX-treated rat pup lungs.

More needs to be said about the effect of thyroid hormones in influencing sensitivity to $\mathrm{O}_{2}$. The findings in the present study that exposure to high $\mathrm{O}_{2}$ significantly reduced serum $\mathrm{T}_{3}$ and $\mathrm{T}_{4}$ levels in sham-treated control rats (and even reduced serum $\mathrm{T}_{4}$ level in the prenatal $\mathrm{TRH}+\mathrm{DEX}$-treated $\mathrm{O}_{2}$ group) are in agreement with the study of Galton (24), which demonstrated a marked fall in the serum concentration of endogenous $\mathrm{T}_{4}$ and a decrease in $\mathrm{T}_{4}$-binding activity in serum with hyperoxia. Smith et al. (25) previously reported that feeding desiccated thyroid or injecting $\mathrm{T}_{4}$ to young rats increased the noxious effects of high $\mathrm{O}_{2}$ exposure. Smith's results are consistent with the previous full-term newborn rat studies from our laboratories in which prenatal TRH administration produced decreased hyperoxic survival and $\mathrm{O}_{2}$ tolerance associated with increased serum $\mathrm{T}_{3}$ and $\mathrm{T}_{4}$ levels (6). For premature rat pups in the present study, however, the similar serum $T_{3}$ and $T_{4}$ increases in prenatal TRH (plus DEX)-treated rats were not associated with inferior tolerance to hyperoxic exposure. These discordant results for the influence of thyroid hormones on $\mathrm{O}_{2}$ sensitivity, as well as the divergent effects of prenatal hormonal treatment on preterm versus full-term newborn rats would seem to be gestationally related.

Finally, our findings of a positive correlation between the ability to augment AOE gene expression and improved lung tolerance to hyperoxic challenge in our hormonally treated premature animals may further support the continued clinical use of prenatal TRH and glucocorticoid treatment in threatened premature deliveries with a high likelihood of requiring assisted ventilation with high $\mathrm{O}_{2}$ therapy. In addition, our data may contribute some understanding of why to date this treatment regimen has had its most pronounced clinical effect on reducing the incidence of bronchopulmonary dysplasia (rather than respiratory distress syndrome).

Acknowledgment. The authors thank Miguel Martinez for his expert technical assistance.

\section{REFERENCES}

1. Morales WJ, O'Brien WF, Angel JL, Knuppel RA, Sawai S 1989 Fetal lung maturation: the combined use of corticosteroids and thyrotropin-releasing hormone. Obstet Gynecol 73:111-116

2. Ballard RA, Ballard PL, Creasy RK, Padbury J, Polk DH, Bracken M, Moya FR, Gross I, and the TRH Study Group 1992 Respiratory disease in very-low-birthweight infants after prenatal thyrotropin-releasing hormone and glucocorticoid. Lancet 339:510-515

3. Cernadas JC, Fustiñana C, Althabe F, Althabe O 1992 Controlled trial of prenatal betamethasone plus TRH for prevention of respiratory distress syndrome (RDS) in preterm infants. Pediatr Res 32:738 (abstr)

4. Rodriguez MP, Sosenko IRS, Antigua MC, Frank L 1991 Prenatal hormone treatment with thyrotropin releasing hormone and with thyrotropin releasing hormone plus dexamethasone delays antioxidant enzyme maturation but does not inhibit a protective antioxidant enzyme response to hyperoxia in newborn rat lung. Pediatr Res 30:522-527

5. Chen Y, Whitney PL, Frank L 1993 Negative regulation of antioxidant enzyme gene expression in the developing fetal rat lung by prenatal hormonal treatments. Pediatr Res 33:171-176

6. Rodriguez-Pierce M, Sosenko IRS, Frank L 1992 Prenatal thyroid releasing hormone and thyroid releasing hormone plus dexamethasone lessen the survival of newborn rats during prolonged high $\mathrm{O}_{2}$ exposure. Pediatr Res 32:407-411

7. Chen X, Whitney PL, Frank L 1994 Comparative responses of premature versus full-term newborn rats to prolonged hyperoxia. Pediatr Res 35:233-237

8. Chen Y, Frank L 1993 Differential gene expression of antioxidant enzymes in the perinatal rat lung. Pediatr Res 34:27-31

9. Hass MA, Iqbal J, Clerch LB, Frank L, Massaro D 1989 Rat lung Cu, Zn superoxide dismutase. Isolation and sequence of a full-length cDNA and studies of enzyme induction. J Clin Invest 83:1241-1246

10. Durnam DM, Palmiter RD 1983 A practical approach for quantitating specific mRNAs by solution hybridization. Anal Biochem 131:385-393

11. McCord JM, Fridovich I 1969 Superoxide dismutase: an enzymic function for erythrocuprein (hemocuprein). J Biol Chem 244:6049-6055

12. Holmes RS, Masters CJ 1970 Epigenetic interconversions of the multiple forms of mouse liver catalase. FEBS Let 11:45-48

13. Paglia DE, Valentine WN 1967 Studies on the quantitative and qualitative characterization of erythrocyte glutathione peroxidase. J Lab Clin Med 70:158-169

14. Iqbal J, Whitney P 1991 Use of cyanide and diethyldithiocarbamate in the assay of superoxide dismutases. Free Radical Biol Med 10:69-77

15. Schneider WC 1957 Determination of nucleic acids in tissue by pentose analysis Methods Enzymol 3:680-684

16. Bligh EG, Dyer WJ 1959 A rapid method of total lipid extraction and purification. Can J Biochem Physiol 37:911-917

17. Mason RJ, Nellenbogen J, Clements JA 1976 Isolation of disaturated phosphatidylcholine with osmium tetroxide. J Lipid Res 17:281-284

18. Morrison WR 1964 A fast, simple and reliable method for the microdetermination of phosphorus in biological materials. Anal Biochem 7:218-224

19. Lowry OH, Rosebrough NJ, Farr AL, Randall RJ 1951 Protein measurement with the Folin phenol reagent. J Biol Chem 193:265-275

20. Steel RGD, Torrie JH 1960 Principles and Procedures of Statistics. McGraw-Hill, New York, pp 107-114

21. Shull S, Heintz NH, Periasamy M, Manohar M, Janssen YMW, Marsh JP, Mossman BT 1991 Differential regulation of antioxidant enzymes in response to oxidants. J Biol Chem 266:24398-24403

22. Jornot L, Junod AF 1992 Response of human endothelial cell antioxidant enzymes to hyperoxia. Am J Respir Cell Mol Biol 6:107-115

23. Clerch LB, Massaro D 1992 Rat lung antioxidant enzymes: differences in perinatal gene expression and regulation. Am J Physiol 263:L466-L470

24. Galton VA 1978 Role of thyroid gland in oxygen toxicity Am J Physiol 235:E628 E633

25. Smith CW, Bean JW, Bauer R 1960 Thyroid influence in reactions to $\mathrm{O}_{2}$ at atmospheric pressure. Am J Physiol 199:883-888 